\title{
BMJ Open Cohort Profile: Perinatal depression and child socioemotional development ; the Bachpan cohort study from rural Pakistan
}

Siham Sikander, ${ }^{1,2}$ Ikhlaq Ahmad, ${ }^{1}$ Lisa M Bates, ${ }^{3}$ John Gallis, ${ }^{4,5}$ Ashley Hagaman, ${ }^{6}$ Karen O'Donnell, ${ }^{5}$ Elizabeth Louise Turner, ${ }^{5,7}$ Ahmed Zaidi, ${ }^{1}$ Atif Rahman, ${ }^{8}$ Joanna Maselko 6,9

To cite: Sikander S, Ahmad I, Bates LM, et al. Cohort Profile: Perinatal depression and child socioemotional development ; the Bachpan cohort study from rural Pakistan. BMJ Open 2019;9:e025644. doi:10.1136/ bmjopen-2018-025644

- Prepublication history for this paper is available online. To view these files, please visit the journal online (http://dx.doi org/10.1136/bmjopen-2018025644).

Received 22 August 2018 Revised 20 December 2018 Accepted 8 March 2019

\section{Check for updates}

(c) Author(s) (or their employer(s)) 2019. Re-use permitted under CC BY-NC. No commercial re-use. See rights and permissions. Published by BMJ.

For numbered affiliations see end of article.

\section{Correspondence to} Dr Siham Sikander; siham.sikander@hdrfoundation. org

\section{ABSTRACT}

Purpose This is a prospective pregnancy-birth cohort designed to investigate the effects of depression on socioemotional development of children. Perinatal depression is a risk factor for poor child development and for many it has a recurring chronic course. Thus, the exposure to depression can continue through the early years of the child with detrimental developmental outcomes.

Participants Between 0ctober 2014 and February 2016, we recruited 1154 pregnant women from a rural subdistrict of Pakistan. Data include longitudinal and repeated measures of maternal psychosocial measures and child growth, cognitive and socioemotional measures. Follow-up include mother-child dyad assessments at 3rd, 6th, 12th, 24th and 36th months of child age. All these follow-ups are community based at the household level. We have competed baseline assessment.

Findings to date of the eligible dyads, we followed $885(76.6 \%), 929(91 \%)$ and $940(93.3 \%)$ at 3, 6 and 12 months post-childbirth. We include a subsample mother-child dyad DNA and inflammatory biomarkers, 73 and 104, respectively.

Future plans While we continue to do 24-month and 36-month follow-up assessments, we plan to follow these mother-child dyads up to the age of 7-8 years with some children being exposed to at least 1 year of school environment. Investigators interested in learning more about the study can contact (jmaselko@unc.edu) and (siham.sikander@hdrfoundation.org).

\section{INTRODUCTION}

Perinatal depression is an episode of depression occurring either during pregnancy, within 1 year after delivery, or both. ${ }^{2}$ The prevalence of perinatal depression is high in low/middle-income countries (LMIC), with a prevalence of $>30 \%$ reported in south Asian countries like Pakistan. ${ }^{34}$ While being highly prevalent, it also has a recurring and chronic course. ${ }^{5-7}$ It is more common among poorer women exposed to gender-based risks (eg, intimate partner violence, son preference,
Strengths and limitations of this study

- The main strengths include hypothesis-led investigation, use of robust study design and a multidisciplinary team to answer multiple research questions broadly related to the topic of maternal depression and child developmental trajectories.

- Multiple interim assessments in between the third trimester of pregnancy and 36-month postnatal follow-ups, using validated instruments, provide a rigorous design in analysing the relationship between changes in maternal depressive symptoms and child outcomes.

- Relatively low loss to follow-up rates at each assessment wave.

- Missing data due to attrition are usual in cohorts, statistical approaches will be used to minimise bias.

- One of the only pregnancy-birth cohort of perinatal depression being followed in a low-resource setting or low/middle-income countries.

role restrictions around housework and infant care) and/or those with a psychiatric history. ${ }^{4}$ A number of systematic reviews from LMIC and high income countries (HIC) indicate that child health outcomes are negatively associated with perinatal depression. ${ }^{8-12}$ For example, recent studies highlight the effects of perinatal depression on child socioemotional and cognitive developmental outcomes. ${ }^{13-15}$ Negative effects of symptoms of depression for the child start as early as in pregnancy and can be observed lasting into adulthood. ${ }^{1416}$ Reducing perinatal depression and improving outcomes in the next generation is thus a global public health priority. ${ }^{3} 1718$

Although observational evidence shows that reductions in depressive symptomology are associated with improvements in child outcomes, experimental evidence from interventions to mitigate maternal depression has 


\section{Box 1 Summary of the cohort profile}

Profile in a nutshell Profile in a nutshell

- The perinatal depression cohort is a prospective pregnancy and birth cohort designed to investigate the effects of depression on cognitive and socioemotional development among children.

- Between October 2014 and February 2016, we recruited 1154 pregnant women from a rural subdistrict of Pakistan.

- Longitudinal follow-up includes mother-child dyad assessments at 3rd, 6th, 12th, 24th and 36th month postnatal. All these follow-ups are community based at the household level. Of 1021 live-born children, all are eligible for follow-up and 940 have been followed up at 12 months postnatal.

- Data include longitudinal and repeated measures of maternal psychosocial measures and child growth, cognitive and socioemotional measures. Data also include a subsample mother-child dyad DNA and inflammatory biomarker.

- Investigators interested in learning more about the study can email [jmaselko@unc.edu] and [siham.sikander@hdrfoundation.org].

not been as consistent. Many studies have not found a sustained impact on child outcomes when perinatal or maternal depression was treated. ${ }^{19-21}$ This inconsistency across studies is likely attributable to differences in design features such as length of follow-up, ${ }^{22}$ choice of comparison groups, unaddressed endogeneity ${ }^{2324}$ and enrolment age differences (eg, infants aged 1-18 months). ${ }^{19}$ 25-31 Apart from these limitations, the perinatal mental health interventions themselves are also varied in their content and intensity. There is evidence from LMIC that effective interventions for perinatal depression ${ }^{32}$; the majority of these interventions are front loaded, with booster sessions lasting until at most 3-6 months postnatal, which may not address the recurring nature of depression or its chronicity in the longer term. ${ }^{32}$ Finally, evaluations of depression interventions also do not typically account for important contextual factors, such as chronic exposure to intimate partner violence, a known risk factor for poor maternal mental health, which may influence their efficacy. $^{32} 33$

With this backdrop, we established a pregnancy-birth cohort, called Bachpan (the word Bachpan means childhood in the local Urdu language) cohort study, to follow-up the mother-child dyads through 36 months postnatal and beyond. We recruited both prenatally depressed and non-depressed pregnant women in our cohort to be seen at 3, 6, 12 and 24 months of child age before a final assessment at 36 months (see box 1). The multiple, frequent and long-term mother-child dyad follow-ups will enable rigorous analyses of the relationship between changes in women's depressive symptoms and child outcomes like the socioemotional, cognitive and growth, in terms of multiple cofactors that mediate the risk and underscore the potentially modifiable risk factors and time varying mechanisms. Alongside the cohort with its child outcomes, a peer-delivered perinatal depression intervention with outcomes of remission/

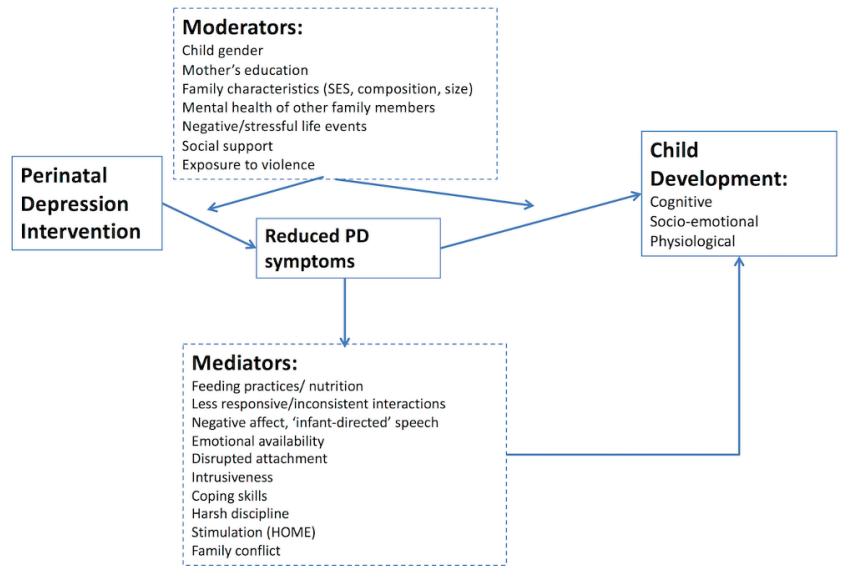

Figure 1 Theoretical model of perinatal depression and child outcomes. HOME, home observation for measurement of the environment; SES, socio-economic status; PD, perinatal depression.

recovery at 6 and 36 months postnatal is also tested in randomised trials ${ }^{345}$ (see figure 1 -conceptual model).

\section{COHORT DESCRIPTION}

Between October 2014 and February 2016, we enrolled prenatally depressed and non-depressed pregnant women to participate in this pregnancy-birth cohort study. The cohort is based in Kallar Syedan, which is one of the seven rural subdistricts of Rawalpindi in Pakistan. Kallar Syedan has a population of 190000-250000; the average household consists of 6.2 members. Most families depend on subsistence farming, supported by earnings of one or more adult male members serving in the armed forces, working as government employees or performing semiskilled or unskilled labour in the cities. The subdistrict is representative of a typical low-socioeconomic rural area of Pakistan. Male and female literacy rates are $80 \%$ and $50 \%$, respectively, and infant mortality is $\sim 84$ per 1000 live births. ${ }^{3637}$

We identified pregnant women through the registers of government-employed community health workers called Lady Health Workers (LHWs). One of the statutory duties of LHWs is to register new pregnancies in their catchment area. All potentially eligible women were informed about the study by the LHWs. To be eligible for the study women had to be married, in the third trimester of pregnancy ( $\geq 28$ weeks of gestation), at least 18 years of age and intending to reside in the study area, not require immediate inpatient care for any reason (medical or psychiatric) and be able to speak Urdu, Punjabi or Potohari languages. All eligible women were approached by research staff for informed consent and screened for depression with the Patient Health Questionnaire-9 (PHQ-9). Those scoring $\geq 10$ on the PHQ-9 formed the prenatally depressed group with 'moderate to severe' endorsement of symptoms of depression. For every woman who screened positive for depression, the next woman in that village who scored $<10$ on the PHQ-9 


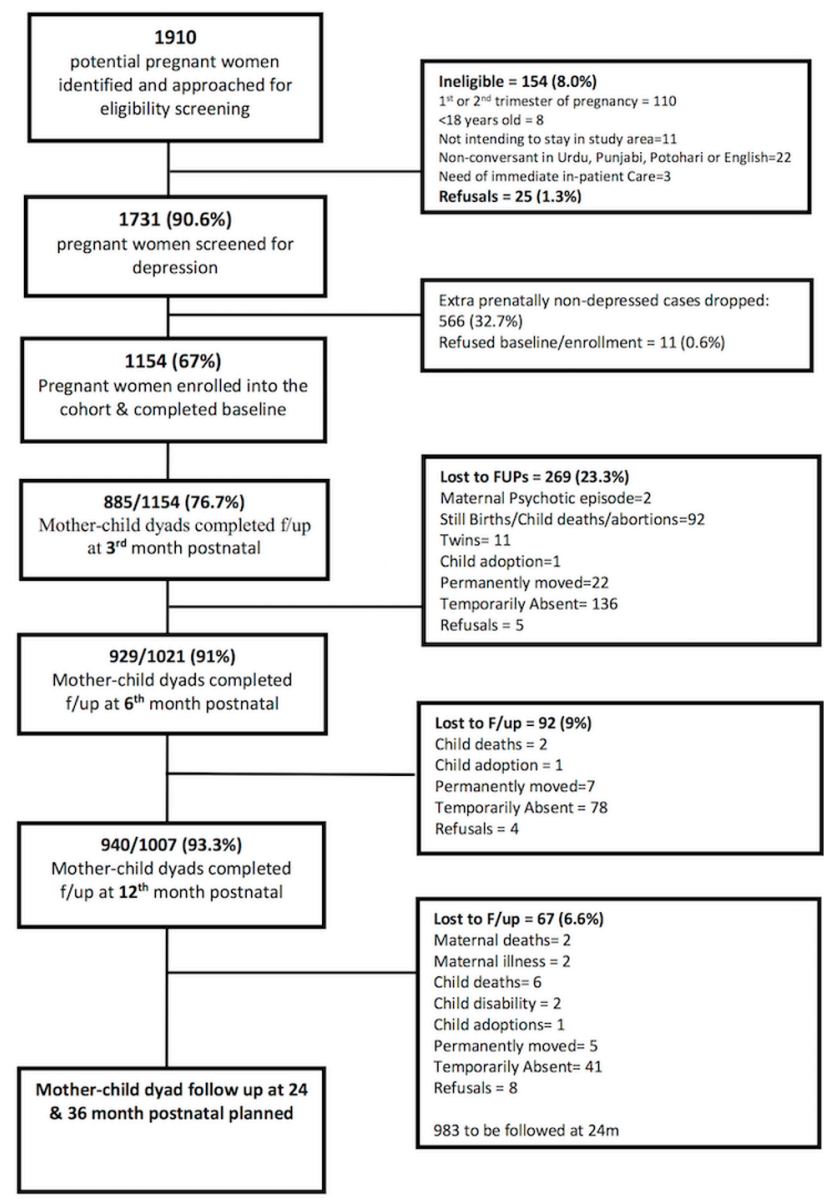

Figure 2 Cohort profile: flowchart.

was invited to participate as part of the non-exposed arm of the cohort, resulting in a 1:1 ratio of prenatally 'depressed' and 'non-depressed' in the sample. Immediately after the screening, all participants were approached for their baseline assessments. All screening, baseline and follow-up assessments were done by trained research assistants (graduates and maters in social science, psychology and behavioural science).

In all, 1910 pregnant women were approached. Of these, $154(8 \%)$ were ineligible by the criteria above, 25 $(1.3 \%)$ refused to participate at the eligibility screening stage.

The remaining 1731 (90.6\%) eligible pregnant women were screened for depression. In all, we enrolled 1154 pregnant women in the Bachpan cohort study; out of these 570 were depressed and 584 non-depressed according to the PHQ-9 cut-offs mentioned above. Only $11(0.64 \%)$ refused enrolment into the cohort. We dropped/excluded $566(32.7 \%)$ pregnant women who were non-depressed since they were over and above the sample we required (see figure 2).

After collecting prenatal baseline information, each mother-child dyad is followed up at child age 3, 6, 12, 24 and 36 months. The follow-ups are scheduled using the birth dates of the index children from registers of the same LHWs who registered these pregnant women. We intend following this birth cohort at 7-8 years of child age, by that time majority of the children would have had at least 1 year of school exposure.

All follow-up interviews are conducted face-to-face, either at the woman's home or the LHW's house. The follow-up rates at 3, 6 and 12 months have been $76.7 \%$, $91 \%$ and $93 \%$, respectively. The lower attrition rates thus far are due to the process by which we engage with the community and households through the resident community health workers called LHWs. Coupled by the convenience of being interviewed at participants' preferred place and time adds to minimising the overall attrition. Lastly, the women who miss any follow-ups are ensured that they are followed up in the subsequent follow-up assessment. The 24-month follow-up will be completed in August 2018 and the 36-month postnatal follow-up assessments are scheduled for August 2019. Baseline characteristics did not differ significantly between those missing and those present at each of the follow-up time points

\section{MEASUREMENTS}

Child growth and development and maternal depression at 36 months postnatally are the main outcomes of interest. We also incorporate a comprehensive set of measures of potential exposures, moderators, mediators and confounders relevant to numerous etiological questions of interest that this cohort may address. What follows is the details of the constructs and measures used, broadly divided into two categories (1) maternal and (2) child (see table 1).

\section{MATERNAL CONSTRUCTS AND MEASURES Sociodemographics}

Information on the women's age and level of education; their husbands' occupation, income, assets, economic shocks and debt; and the household structure are assessed. We also ask about the household's overall socioeconomic status through the LHW-based subjective measure previously used in our studies. ${ }^{38}$ It is a 5-point likert scalebased measurement with 1 being richest and 5 being the poorest. LHWs being residents of the same community and the village, where the participants live, have intimate knowledge of the overall socioeconomic status of all the households in their catchment area.

Since socioeconomic measurements are challenging to record accurately, we use this measure especially in combination with debt alongside other measures to help us create accurate categories which are also sensitive to change over time.

\section{Psychosocial factors}

Perinatal depression was assessed longitudinally using the PHQ-9; we used the $\geq 10$ cut-off for enrolling pregnant women into the trial portion of the cohort. The PHQ-9 inquires about frequency of depressive symptoms in the last 2 weeks. It has been validated and used extensively in 
Table 1 Summary of constructs and assessments points for the cohort

\begin{tabular}{|c|c|c|c|c|c|c|c|}
\hline \multirow[b]{2}{*}{ Constructs } & \multirow[b]{2}{*}{ Measured/assessed } & \multirow{2}{*}{$\begin{array}{l}\text { Antenatal } \\
\text { Baseline }\end{array}$} & \multicolumn{5}{|l|}{ Postnatal } \\
\hline & & & 3months & 6 months & 12 months & 24 months & 36 months \\
\hline \multicolumn{8}{|l|}{ Maternal constructs } \\
\hline \multirow[t]{5}{*}{ Psychosocial } & Perinatal depression & $\bullet$ & - & - & & - & - \\
\hline & Social support, instrumental and emotional & • & - & $\bullet$ & • & • & • \\
\hline & Decision-making, autonomy and self-efficacy & $\bullet$ & & & $\bullet$ & $\bullet$ & • \\
\hline & Disability/function & • & - & - & • & • & • \\
\hline & Intimate partner violence & • & & & - & $\bullet$ & - \\
\hline \multirow[t]{2}{*}{ Physical health } & $\begin{array}{l}\text { Height, weight, waist circumference, blood } \\
\text { pressure }\end{array}$ & $\bullet$ & $\bullet$ & $\bullet$ & - & $\bullet$ & $\bullet$ \\
\hline & Family planning/contraception use & $\bullet$ & & $\bullet$ & $\bullet$ & $\bullet$ & $\bullet$ \\
\hline \multirow[t]{8}{*}{$\begin{array}{l}\text { Other constructs of } \\
\text { interest }\end{array}$} & $\begin{array}{l}\text { Family history of mental illness and substance } \\
\text { use }\end{array}$ & $\bullet$ & & & & & \\
\hline & Religiosity & $\bullet$ & & & & & \\
\hline & Understanding and executive function & $\bullet$ & & & & & \\
\hline & Life satisfaction & $\bullet$ & & & $\bullet$ & & \\
\hline & Significant life events & $\bullet$ & & & - & $\bullet$ & \\
\hline & Health services utilisation (maternal and child) & & $\bullet$ & $\bullet$ & & $\bullet$ & $\bullet$ \\
\hline & Risk taking & $\bullet$ & & & - & & \\
\hline & Adverse childhood experiences & & & & & & $\bullet$ \\
\hline \multirow[t]{4}{*}{ Child interaction } & $\begin{array}{l}\text { Father and household involvement in parenting } \\
\text { and childcare }\end{array}$ & & $\bullet$ & & $\bullet$ & $\bullet$ & $\bullet$ \\
\hline & Home environment for child rearing/parenting & & $\bullet$ & & $\bullet$ & & $\bullet$ \\
\hline & Postnatal attachment & & $\bullet$ & $\bullet$ & & & \\
\hline & Mother-child interaction & & $\bullet$ & & & $\bullet$ & $\bullet$ \\
\hline \multirow{4}{*}{$\begin{array}{l}\text { Child health and } \\
\text { development }\end{array}$} & Weight, length/height and head circumference & & $\bullet$ & $\bullet$ & $\bullet$ & - & $\bullet$ \\
\hline & Acute illness history & & - & - & - & & \\
\hline & Socioemotional development & & & $\bullet$ & - & $\bullet$ & - \\
\hline & Cognitive development & & & & - & & - \\
\hline \multicolumn{8}{|c|}{ Maternal and child biomarkers (subsample) } \\
\hline \multirow[t]{2}{*}{ Hormone } & Hair steroid hormones (mother) & & & & - & & \\
\hline & Hair steroid hormones (child) & & & & $\bullet$ & & \\
\hline \multirow[t]{2}{*}{ Genetic } & DNA (mother) & - & - & & & & \\
\hline & DNA (child) & & $\bullet$ & & & & \\
\hline
\end{tabular}

the region. ${ }^{3940}$ Given that the PHQ-9 is a screening tool, we used the Structured Clinical Interview for DSM IV Disorders (SCID) module for current major depressive episode as a diagnostic tool and to assess the criterion-related validity of using the scores from the PHQ-9 to measure the number of symptoms endorsed by the woman over time. The diagnostic and statistical manual of mental disorders (DSM) IV diagnosis of current major depressive 
episode is generated through the SCID algorithm. SCID is a semistructured interview for the diagnoses of psychiatric disorders. ${ }^{41}$ It has been cross-culturally adapted for assessing depression among women during pregnancy and in the postpartum period. ${ }^{42}$

\section{Perceived stress}

Women's subjective experience of their stress is assessed with the 10-item Cohen's Perceived Stress Scale (PSS).$^{434}$ It is a tool designed to measure the degree to which situations in one's life are apprised to be stressful.

\section{Social support}

We use three instruments to capture both emotional and instrumental support. The Multidimensional Scale of Perceived Social Support is used as a measure of subjectively assessed social support. ${ }^{45}$ It has been adapted for Pakistani settings and used extensively in the study area. ${ }^{3846}$ It has 12 items rated on a 7-point likert scale with subdomains capturing perceived support from significant other, family and friends. We use the Maternal Social Support Index as a measure of instrumental support. It consists of 21 questions which inquire about the availability of support to the woman in her daily tasks. ${ }^{47}$

An interview regarding who is caring for the child during daily instrumental and social activities, a Day-inLife (DIL) was developed for the study to assess relative support in caregiving that the depressed and non-depressed groups of mothers' report.

\section{Maternal self-efficacy}

We use the 10-item Maternal Self-Efficacy Scale to assess a woman's beliefs about her ability to take care of her child compared with other mothers she has seen. ${ }^{48}$ This tool has been used extensively in research on maternal depression and child development, in both high/low-income countries. ${ }^{49-51}$

\section{Physical health \\ Disability}

The WHO Disability Assessment Schedule (WHO-DAS) is used to assess women's disability. It is a 12-item questionnaire that assesses levels of functionality over the last 30 days. Combined with two items about one's ability to work in the last 30 days, the WHO-DAS generates a total disability score, quality adjusted life years and number of days the respondent is not able to work. ${ }^{52}$

Height, weight, waist circumference and the blood pressure of women are measured at each encounter. We also assess obstetric history including number of pregnancies, live births and contraception being used or not.

\section{Intimate partner violence (IPV)}

We assess IPV using the WHO Violence Against Women Instrument. ${ }^{53}$ It minimises reporting biases by asking only about specific behaviours perpetrated by a male partner, rather than ascertaining if a woman subjectively perceives she has experienced 'abuse' or 'violence'. The tool addresses three types of violence (1) physical,
(2) psychological and (3) sexual, severity, timing and frequency. For the cohort, we adapted the instrument for ease of administration, and only referenced the respondent's husband as the perpetrator.

\section{Other maternal measures of interest}

Women's history of mental illness, substance abuse among family members, the mother's engagement in traditional rituals (such as chilla which is a 40-day period when a woman is relieved of household responsibilities after child birth $)^{54}$ and significant negative life events in the past 1 year. ${ }^{54}$ We also administer the Client Services Receipt Inventory ${ }^{55}$ to record health services sought during the perinatal period. This will enable us to asses cost-effectiveness of the intervention tested in the cohort (see the child constructs and measures section). ${ }^{3456} \mathrm{We}$ also assess women's decision-making, autonomy, religiosity, risk taking, bonding with her parents (using the Parental Bonding Instrument [PBI] $)^{5758}$ and her adverse childhood experiences (including physical and psychological abuse, neglect and several sorts of family dysfunction). ${ }^{5960}$

\section{CHILD CONSTRUCTS AND MEASURES \\ Child nutrition and care}

We assess breastfeeding practices in accordance with WHO guidelines, as well as complementary feeding and food diversity, in terms of frequency and quantity. ${ }^{61} 62$ We also ascertain beliefs, practices and expectations of mothers for their children with respect to vaccination coverage.

\section{Child interaction}

\section{Observation of mother-child interaction (OMCI)}

We adapted the OMCI, which is a tool to evaluate responsive parenting through direct, 3-5 min OMCIs around a picture book activity. OMCI was developed and used in Pakistan for 12, 24 and 48 months old children. ${ }^{63}$

Home observation for measurement of the environment (HOME) inventory

We use HOME as a measure of maternal responsiveness and the overall conduciveness of the home environment for child rearing. It is an extensively used measure of the child's family environment ${ }^{64}$ and it has been validated in Pakistan. ${ }^{65-67}$

\section{Attachment relationship}

We assess the maternal attachment with the child through the 19-item Maternal Postnatal Attachment Scale. ${ }^{68}$ It has been used extensively across settings.

\section{Child caregiving practices}

The DiL tool is a semistructured interview using a narrative-elicitation technique, designed to elicit in detail the involvement of the mother as well as other family members in daily care of the infant. The DiL tries to create a narrative about who the child spends time with by 


\begin{tabular}{|c|c|c|}
\hline $\begin{array}{l}\text { Baseline maternal and } \\
\text { household measures }\end{array}$ & $\begin{array}{l}\text { Total unweighted } \\
(\mathrm{n}=1154), \% \\
\text { and means (SD) }\end{array}$ & $\begin{array}{l}\text { Weighted, } \\
\% \text { and means (SD) }\end{array}$ \\
\hline Age & $26.7(4.5)$ & $26.6(5.5)$ \\
\hline \multicolumn{3}{|l|}{ Education (grades passed) } \\
\hline Women & $7.7(4.5)$ & $8.1(5.5)$ \\
\hline Husbands & $8.6(3.4)$ & $8.8(4.1)$ \\
\hline \multicolumn{3}{|l|}{ Women's occupation } \\
\hline Housewives & $93.80 \%$ & $93.70 \%$ \\
\hline Manual or skilled work & $6.20 \%$ & $6.30 \%$ \\
\hline \multicolumn{3}{|l|}{ Husband's occupation } \\
\hline Unemployed & $9 \%$ & $8 \%$ \\
\hline Manual work & $91.20 \%$ & $90.90 \%$ \\
\hline Skilled work & $8.70 \%$ & $9.10 \%$ \\
\hline
\end{tabular}

Asset-based SES variable cut into quintiles

\begin{tabular}{|c|c|c|}
\hline Lowest quintile & $19.90 \%$ & $17.10 \%$ \\
\hline Lower middle quintile & $20.00 \%$ & $18.60 \%$ \\
\hline Middle quintile & $20.00 \%$ & $20.20 \%$ \\
\hline Upper middle quintile & $20.00 \%$ & $21.80 \%$ \\
\hline Upper quintile & $20.00 \%$ & $22.30 \%$ \\
\hline \multicolumn{3}{|l|}{ Household structure } \\
\hline Nuclear & $22.50 \%$ & $21.90 \%$ \\
\hline Joint/extended & $65.80 \%$ & $67.20 \%$ \\
\hline Multiple households & $11.70 \%$ & $10.90 \%$ \\
\hline \multicolumn{3}{|l|}{ Number of living children } \\
\hline First pregnancy & $30.20 \%$ & $32.20 \%$ \\
\hline 1-3 children & $60.10 \%$ & $59.80 \%$ \\
\hline$>4$ children & $9.20 \%$ & $7.90 \%$ \\
\hline \multicolumn{3}{|l|}{ Gender of the children } \\
\hline Girls < 18years of age & $1.4(1.6)$ & $1.4(2.0)$ \\
\hline Boys $<18$ years of age & $1.3(1.6)$ & $1.3(1.9)$ \\
\hline PHQ-9 scores & $8.7(6.7)$ & $6.7(7.7)$ \\
\hline SCID current MDE & $38.30 \%$ & $26.60 \%$ \\
\hline PSS scores & $17.7(9.0)$ & $15.8(10.6)$ \\
\hline MSPSS scores & $4.5(1.3)$ & $4.6(1.5)$ \\
\hline WHO-DAS scores & $10.9(9.4)$ & $9.1(10.9)$ \\
\hline \multicolumn{3}{|l|}{ IPV in last 12 months } \\
\hline Physical violence & $15.90 \%$ & $12.80 \%$ \\
\hline Psychological violence & $38 \%$ & $32.80 \%$ \\
\hline Sexual violence & $31.20 \%$ & $29.20 \%$ \\
\hline Life events (last 12 months) & $3.6(2.4)$ & 3.4 (2.9) \\
\hline
\end{tabular}

PKR, local currency.

IPV, Intimate Partner Violence; MPSS, Multidimensional Scale of Perceived Social Support; MDE,Major Depressive Episode; PHQ9, Patient Health Questionnaire-9; PSS, Perceived Stress Scale; SCID, Structured Clinical Interview for DSM IV Disorders; WHODAS, WHO Disability Assessment Schedule.

taking an account of all the activities done with the child. This begins with the account starting from early morning instrumental tasks such as who wakes, washes and feeds the infant; similarly, the narrative building continues into the afternoon and night until the time the child sleeps again. The household members like the mother, father, mother-in-law, aunt and so on are recorded against each activity and overall impression of time spent without the mother is made; the data thus provide a detailed picture of both whom the infant spends the day with and what kind of support the mother receives and from whom.

\section{Child growth and development}

We collect anthropometric measurements for physical development (including weight, height and head circumference) based on WHO standards and norms. We also assess diarrheal and acute respiratory illness episodes using WHO definitions.

\section{Strengths and Difficulties Questionnaire (SDQ)}

The SDQ is a screening tool for child's socioemotional/ behavioural development using parental report of 25 child attributes divided into five subscales: emotional symptoms, conduct problems, hyperactivity, peer problems and prosocial behaviour. ${ }^{69} 70$ The SDQ has been extensively translated into 50 other languages (including Urdu) and used in LMIC including the study area. ${ }^{71-73}$

\section{Ages and Stages Questionnaire (ASQ)}

We also use the socioemotional component of the ASQ (ASQ-SE) during the follow-up assessments as well as at the final outcome assessment at 36 months postnatal. ${ }^{74} 75$ The ASQ-SE includes a simple set of 25 questions asking the caregiver to report age-appropriate psychosocial milestones. ${ }^{76}$ It has been widely used. ${ }^{77}$

\section{Bayley Scales of Infant and Toddler Development Third Edition (BSID-III)}

We use the BSID-III, which is an individually administered assessment of the child's achievement of developmental milestones across five areas: cognitive, language, motor, socioemotional and adaptive skills. ${ }^{78}$ Raw scores in each domain are summarised by chronological age-related scaled scores and composite scores for each domain. The child is assessed with the full test at the 12-month contact and with only the receptive language and fine motor domains at 36 moths, due to time demands and also the difficulties involved in administering the language laden instructions in other domains.

\section{Epigenetics and biomarkers (subsamples)}

We conducted a small nested feasibility study of buccal DNA samples from 73 mothers in the third trimester of pregnancy and the same 73 mother-child dyads at 3 months postchild birth (approximately half from prenatally depressed and half from prenatally non-depressed). We also collected, apart from the above, hair samples from 104 mother-child dyads at 12 months postnatal. These components will enable us to examine epigenetic and hair cortisol (and other biomarkers of stress) among depressed versus non-depressed mothers and their children. 
Table 3 Summary of postnatal follow-ups

\begin{tabular}{|c|c|c|c|}
\hline Maternal measures & $\begin{array}{l}\text { 3rd month } \\
\mathrm{n}=885, \% \text { or mean (SD) }\end{array}$ & $\begin{array}{l}\text { 6th month } \\
\mathrm{n}=929, \% \text { or mean }(S D)\end{array}$ & $\begin{array}{l}\text { 12th month } \\
\mathrm{n}=940, \% \text { or mean (SD) }\end{array}$ \\
\hline Response rate & $76.60 \%$ & $91 \%$ & $93.30 \%$ \\
\hline SCID current MDE & $15.30 \%$ & $12.90 \%$ & $18.70 \%$ \\
\hline PSS scores & $19.9(3.8)$ & $19.8(3.7)$ & $20.0(3.4)$ \\
\hline \multicolumn{4}{|l|}{ MSSI scores } \\
\hline Tasks done alone & $2.7(1.6)$ & NA & $2.8(1.8)$ \\
\hline Tasks done by someone else & $2.9(0.9)$ & & $2.8(1.1)$ \\
\hline Tasks shared & $2.4(1.5)$ & & $2.4(1.7)$ \\
\hline Very satisfied & NA & NA & $26.40 \%$ \\
\hline Satisfied & & & $40.90 \%$ \\
\hline Moderately satisfied & & & $24.30 \%$ \\
\hline Dissatisfied & & & $3.00 \%$ \\
\hline Very dissatisfied & & & $2.70 \%$ \\
\hline \multicolumn{4}{|l|}{ Intimate partner violence last 12 months } \\
\hline Physical violence & NA & NA & $10.90 \%$ \\
\hline Psychological violence & & & $33.10 \%$ \\
\hline Responsivity (subscale) & $8.2(2.1)$ & & $9.8(1.3)$ \\
\hline MPAS scores & $87.6(5.7)$ & $86.8(5.4)$ & NA \\
\hline \multicolumn{4}{|l|}{ DiL } \\
\hline Daily waking, bathing, feeding of the child & & NA & \\
\hline Done by mom alone & $87.10 \%$ & & $79.90 \%$ \\
\hline Shared by grandmother, father or others & $9.80 \%$ & & $18 \%$ \\
\hline \multicolumn{4}{|l|}{$\begin{array}{l}\text { Daily interacting, holding, soothing of the } \\
\text { child }\end{array}$} \\
\hline Done by mom alone & $57 \%$ & & $44.60 \%$ \\
\hline $\begin{array}{l}\text { Done by mom alone shared by } \\
\text { grandmother, father or others }\end{array}$ & $30.50 \%$ & & $51.60 \%$ \\
\hline ASQ-SE scores & NA & $9.5(12.2)$ & NA \\
\hline Height for age z-scores & $0.1(1.8)$ & $0.1(1.7)$ & $-0.7(1.3)$ \\
\hline Weight for age z-scores & $-1.1(1.3)$ & $-0.9(1.2)$ & $-0.8(1.1)$ \\
\hline $\begin{array}{l}\text { Immunisation completion (measles vaccination } \\
\text { at } 9 \text { months of infant's age) }\end{array}$ & - & - & $97.10 \%$ \\
\hline BSID scaled scores & & & \\
\hline
\end{tabular}

Continued 
Table 3 Continued

\begin{tabular}{|c|c|c|c|}
\hline Maternal measures & $\begin{array}{l}\text { 3rd month } \\
n=885, \% \text { or mean (SD) }\end{array}$ & $\begin{array}{l}\text { 6th month } \\
n=929, \% \text { or mean (SD) }\end{array}$ & $\begin{array}{l}\text { 12th month } \\
n=940, \% \text { or mean (SD) }\end{array}$ \\
\hline Cognitive & NA & NA & $9.4(2.2)$ \\
\hline Receptive language & & & $8.0(1.4)$ \\
\hline Expressive language & & & $9.1(1.5)$ \\
\hline Fine motor & & & $9.0(1.8)$ \\
\hline Gross motor & & & $8.1(2.3)$ \\
\hline
\end{tabular}

ASQ-SE, socioemotional component of the ASQ; BSID, Bayley Scales of Infant and Toddler Development; DiL, Day-in-Life; HOME-IT, home observation measurement of enviornment infant toddler; MSES, Maternal Self-Efficacy Scale; MPAS, maternal postnatal attachment scale; MSPSS, Multidimensional Scale of Perceived Social Support; MSSI, Maternal Social Support Index; NA, Not Assessed; PHQ-9, Patient Health Questionnaire-9 ; PSS, Perceived Stress Scale; SCID, Structured Clinical Interview for DSM IV Disorders; WHO-DAS, WHO Disability Assessment Schedule.

\section{Patient and public involvement}

No patients were involved in development of the research questions, design of the study or the recruitment.

\section{Data management}

All data are collected electronically via tablets and is uploaded daily onto the main server. Quality checks for consistency, accuracy, missing data and other irregularities are conducted weekly. Any issues are shared with the research team and discussed during a weekly field staff meeting. Data are backed up daily to a secondary server. All data are deidentified/anonymised before being shared with coinvestigators. At all stages/levels, data are password protected with multiple layers of authorisation.

Prior to analysis, we upweighted the mothers whose depression levels were $<10$ on the PHQ-9 in order to make the baseline sample representative of the local population, since only one in three of these women was invited to participate in the study. We generated cluster-specific weights and assigned them to these non-depressed women. Since all of the women who scored a 10 or above on the PHQ-9 were invited to participate, their default weight was 1 .

\section{Findings to date}

In tables 2 and 3, we summarise our key findings to date. To make the 1154 women representative of the local population, we report the weighted values along with the raw (unweighted) numbers at baseline.

\section{Sociodemographics}

The mean age of pregnant women in our cohort is 26.6 years, with an average of 8.1 years of education. Almost all of them being housewives (94\%), with a third of these women being pregnant for the first time (the rest have up to four children); $67.2 \%$ live in a joint family structure. All of these findings are comparable to what we have seen in our previous studies from the same area and what is reported in the national demographic survey. ${ }^{549}$

\section{Maternal psychosocial factors}

At baseline, the mean PHQ-9 and PSS scores were 6.7 and 15.8 showing mild levels of depressive symptoms as well as mild levels of perceived stress. While $26.6 \%$ were found to have major depressive episode on SCID. Rates of major depressive episode are comparable to our previous studies in the same area. ${ }^{3854}$ The stress levels rise marginally while the severity of depressive symptoms go down over time. Overall at baseline (prenatal), 32.8\% and $29.2 \%$ of women experienced psychological and sexual abuse in the last 12 months, respectively, while $15.9 \%$ reported physical violence in the last 12 months. Similarly, a high proportion report experiencing abuse at 12 months postnatal, which other studies also report and is correlated with maternal mental health issues. ${ }^{79} 80$ The support women have (both physical and instrumental) from prenatal to 12 months postnatal is relatively low.

\section{CHILD MEASURES}

The rates of exclusive breastfeeding at 3 and 6 months postnatal were $48 \%$ and $8.7 \%$, respectively. These figures are comparable to what are reported in national surveys as well as from the study area. ${ }^{1179}$ The mean z-scores for both height-for-age and weight-for-age were poor but slightly better than the overall national trends. ${ }^{79}$ Similarly, our cohort at 12 months had a very high vaccination coverage of $97 \%$.

In terms of the responsivity, attachment seems to improve over time as shown by the HOME and MPAS mean scores. Interesting to note is that time spent during the day interacting with the child drops as the child grows older (DiL- $57 \%$ of the time mother interacting, soothing and holding at 3 months vs $44.6 \%$ at 12 months), meaning other family members like the grandmother and the father get more involved.

We do not have normative data on cognitive and socioemotional development of children in Pakistan, especially of this age group. Thus, our values will be most useful for making internal group comparisons as well as observing changes over time. 


\section{MAIN STRENGTHS AND LIMITATIONS}

The main strengths include hypothesis-led investigation, use of robust study design and a multidisciplinary team. Multiple interim assessments in between the third trimester of pregnancy and 36-month postnatal follow-ups provide a rigorous design in analysing the relationship between changes in maternal depressive symptoms and child outcomes. We have taken great care to utilise standardised and validated instruments.

The loss to follow-up rates is relatively low at each assessment wave. However, missing data are common in longitudinal studies, due to attrition or non-response to questionnaire items, and inappropriate handling of missing data can lead to biased statistical interpretation. In addition to likelihood-based statistical methods, which are valid under the missing at random assumption, we will employ multiple imputation to address the issue of missing data, which will help minimise bias and make use of all available data. One of the limitations is not having administered PHQ-9 at 12 months postnatal. Thus, the severity of depressive symptoms across the cohort will not be known-only if they are depressed or not though the diagnostic interview (SCID).

In summary, this pregnancy-birth cohort with a follow-up period of at least 3 years postnatal is well suited to answer multiple research questions broadly related to the topic of maternal depression and child developmental trajectories. We are not aware of any other pregnancybirth cohort of perinatal depression being followed in other low-resource settings or LMIC. The findings are especially relevant for rural based women and children living in LMIC and low-resource settings.

\section{Author affiliations}

${ }^{1}$ Human Development Research Foundation, Islamabad, Pakistan

${ }^{2}$ Public Health, Health Services Academy, Islamabad, Pakistan

${ }^{3}$ Epidemiology, Columbia University Mailman School of Public Health, New York, New York, USA

${ }^{4}$ Biostatistics, Duke University, Durham, North Carolina, USA

${ }^{5}$ Duke Global Health Institute, Duke University, Durham, North Carolina, USA

${ }^{6}$ Carolina Population Center, University of North Carolina at Chapel Hill, Chapel Hill,

North Carolina, USA

${ }^{7}$ Biostatistics and Bioinformatics, Duke University, Durham, North Carolina, USA

${ }^{8}$ Child Mental Health Unit, University of Liverpool, Liverpool, UK

${ }^{9}$ Department of Epidemiology, Gillings School of Global Public Health, University of North Carolina at Chapel Hill, Chapel Hill, North Carolina, USA

Acknowledgements We would like to thank the team at the Human Development Research Foundation (HDRF) including Rakshanda Liaqat, Tayyiba Abbasi, Maria Sharif, Samina Bilal, Quratul-Ain, Anum Nisar, Amina Bibi, Shaffaq Zufiqar, Sonia Khan, Ahmed Zaidi, Ikhlaq Ahmad and Najia Atif. Finally, we are very grateful to the women and their children who are part of this cohort.

Collaborators For any further information or potential collaboration Drs Joanna Maselko (jmaselko@unc.edu) and Siham Sikander (siham.sikander@hdrfoundation. org) can be contacted.

Contributors SS drafted the paper and all authors reviewed and approved it. SS, IA, AR and JM were responsible for the design of the study. SS, IA, LMB, KO, AH and $\mathrm{JM}$ were responsible for data gathering instruments. SS and IA were responsible for the conduct of the cohort. JG, AZ and ELT were responsible for database design and management.

Funding This work was supported by the National Institute of Child Health \& Human Development (NICHD), US to establish the pregnancy-birth cohort and the follow-up of mother-child dyads up to 36 months postnatal under award R01 HD075875.

Competing interests None declared.

Patient consent for publication Obtained.

Provenance and peer review Not commissioned; externally peer reviewed.

Data sharing statement Currently the data are not available since the cohort is ongoing.

Open access This is an open access article distributed in accordance with the Creative Commons Attribution Non Commercial (CC BY-NC 4.0) license, which permits others to distribute, remix, adapt, build upon this work non-commercially, and license their derivative works on different terms, provided the original work is properly cited, appropriate credit is given, any changes made indicated, and the use is non-commercial. See: http://creativecommons.org/licenses/by-nc/4.0/.

\section{REFERENCES}

1. Brenda MY, Leung ND, Bonnie JK, et al. Risks, and the nutrition link - a review of the literature. J Am Diet Assoc 2009;109:1566-75.

2. Gavin NI, Gaynes BN, Lohr KN, et al. Perinatal depression: a systematic review of prevalence and incidence. Obstet Gynecol 2005;106:1071-83.

3. Parsons CE, Young KS, Rochat TJ, et al. Postnatal depression and its effects on child development: a review of evidence from low- and middle-income countries. Br Med Bull 2012;101:57-79.

4. Fisher J, Cabral de Mello M, Patel V, et al. Prevalence and determinants of common perinatal mental disorders in women in low- and lower-middle-income countries: a systematic review. Bull World Health Organ 2012;90:139-49.

5. Maselko J, Sikander S, Bangash O, et al. Child mental health and maternal depression history in Pakistan. Soc Psychiatry Psychiatr Epidemiol 2016;51:49-62.

6. Maselko J, Sikander S, Bhalotra S, et al. Effect of an early perinatal depression intervention on long-term child development outcomes: follow-up of the Thinking Healthy Programme randomised controlled trial. Lancet Psychiatry 2015;2:609-17.

7. Rahman A, Creed F. Outcome of prenatal depression and risk factors associated with persistence in the first postnatal year: prospective study from Rawalpindi, Pakistan. J Affect Disord 2007;100:115-21.

8. Harpham T, Huttly S, De Silva MJ, et al. Maternal mental health and child nutritional status in four developing countries. J Epidemiol Community Health 2005;59:1060-4.

9. Rahman A, Lovel H, Bunn J, et al. Mothers' mental health and infant growth: a case-control study from Rawalpindi, Pakistan. Child Care Health Dev 2004;30:21-7.

10. Rahman A, Iqbal Z, Bunn J, et al. Impact of maternal depression on infant nutritional status and illness: a cohort study. Arch Gen Psychiatry 2004;61:946-52.

11. Rahman A, Hafeez A, Bilal R, et al. The impact of perinatal depression on exclusive breastfeeding: a cohort study. Matern Child Nutr 2016;12.

12. Patel V, DeSouza N, Rodrigues M. Postnatal depression and infant growth and development in low income countries: a cohort study from Goa, India. Arch Dis Child 2003;88:34-7.

13. Herba CM, Glover V, Ramchandani PG, et al. Maternal depression and mental health in early childhood: an examination of underlying mechanisms in low-income and middle-income countries. Lancet Psychiatry 2016;3:983-92.

14. Bennett IM, Schott W, Krutikova S, et al. Maternal mental health, and child growth and development, in four low-income and middleincome countries. J Epidemiol Community Health 2016;70:168-73.

15. Satyanarayana VA, Lukose A, Srinivasan K. Maternal mental health in pregnancy and child behavior. Indian J Psychiatry 2011;53:351-61.

16. Halfon N, Larson K, Lu M, et al. Lifecourse health development: past, present and future. Matern Child Health J 2014;18:344-65.

17. Almond P. Postnatal depression: a global public health perspective. Perspect Public Health 2009;129:221-7.

18. Rahman A, Patel V, Maselko J, et al. The neglected ' $m$ ' in $\mathrm{MCH}$ programmes--why mental health of mothers is important for child nutrition. Trop Med Int Health 2008;13:579-83.

19. Siegenthaler E, Munder T, Egger M. Effect of preventive interventions in mentally ill parents on the mental health of the offspring: systematic review and meta-analysis. J Am Acad Child Adolesc Psychiatry 2012;51:8-17.

20. Forman DR, O'Hara MW, Stuart S, et al. Effective treatment for postpartum depression is not sufficient to improve the developing mother-child relationship. Dev Psychopathol 2007;19:585-602. 
21. Gunlicks ML, Weissman MM. Change in child psychopathology with improvement in parental depression: a systematic review. J Am Acad Child Adolesc Psychiatry 2008;47:379-89.

22. Toth SL, Rogosch FA, Manly JT, et al. The efficacy of toddler-parent psychotherapy to reorganize attachment in the young offspring of mothers with major depressive disorder: a randomized preventive trial. J Consult Clin Psychol 2006;74:1006-16.

23. Wickramaratne P, Gameroff MJ, Pilowsky DJ, et al. Children of depressed mothers 1 year after remission of maternal depression: findings from the STAR*D-Child study. Am J Psychiatry 2011;168:593-602.

24. Barker ED, Copeland W, Maughan B, et al. Relative impact of maternal depression and associated risk factors on offspring psychopathology. Br J Psychiatry 2012;200:124-9.

25. Murray L, Cooper PJ, Wilson A, et al. Controlled trial of the shortand long-term effect of psychological treatment of post-partum depression: 2. Impact on the mother-child relationship and child outcome. Br J Psychiatry 2003;182:420-7.

26. van Doesum KT, Riksen-Walraven JM, Hosman CM, et al. A randomized controlled trial of a home-visiting intervention aimed at preventing relationship problems in depressed mothers and their infants. Child Dev 2008;79:547-61.

27. Fryer RG, Levitt SD. Testing for Racial Differences in the Mental Ability of Young Children. American Economic Review forthcoming

28. Cicchetti D, Rogosch FA, Toth SL. The efficacy of toddler-parent psychotherapy for fostering cognitive development in offspring of depressed mothers. J Abnorm Child Psychol 2000;28:135-48.

29. Hart S, Field T, Nearing G. Depressed mothers' neonates improve following the MABI and a Brazelton demonstration. J Pediatr Psychol 1998;23:351-6.

30. Sharp D, Hay DF, Pawlby S, et al. The impact of postnatal depression on boys' intellectual development. J Child Psychol Psychiatry 1995;36:1315-36.

31. Goodman SH, Rouse MH, Connell AM, et al. and Child Psychopathology: A Meta-Analytic Review. Clin Child Fam Psychol Rev 2011;14:1-27.

32. Rahman A, Fisher J, Bower P, et al. Interventions for common perinatal mental disorders in women in low- and middle-income countries: a systematic review and meta-analysis. Bull World Health Organ 2013;91:593-601.

33. Ali TS, Mogren I, Krantz G. Intimate partner violence and mental health effects: a population-based study among married women in Karachi, Pakistan. Int J Behav Med 2013;20:131-9.

34. Sikander S, Lazarus A, Bangash $\mathrm{O}$, et al. The effectiveness and costeffectiveness of the peer-delivered Thinking Healthy Programme for perinatal depression in Pakistan and India: the SHARE study protocol for randomised controlled trials. Trials 2015;16:015-1063.

35. Turner EL, Sikander S, Bangash O, et al. The effectiveness of the peer delivered Thinking Healthy Plus (THPP+) Programme for maternal depression and child socio-emotional development in Pakistan: study protocol for a three-year cluster randomized controlled trial. Trials 2016;17:016-1530.

36. World Development Indicators 2013. Washington, DC: World Bank, 2013

37. PDHS. Pakistan Demographic and Health Survey - Preliminary Report. Islamabad, Pakistan: National Institute of Population Studies, 2012-13.

38. Rahman A, Malik A, Sikander S, et al. Cognitive behaviour therapybased intervention by community health workers for mothers with depression and their infants in rural Pakistan: a cluster-randomised controlled trial. The Lancet 2008;372:902-9.

39. Patel V, Araya R, Chowdhary N, et al. Detecting common mental disorders in primary care in India: a comparison of five screening questionnaires. Psychol Med 2008;38:221-8.

40. Fraz K, Khan S A, Sikander S. Screening for depression in coronary artery disease patients using PHQ-9. theHealth 2013;4:3-6.

41. First MB, Spitzer RL, Gibbon M. SCID-I/NP (for DSM-IV) Nonpatient Edition. Structured Clinical Interview for DSM-IV-TR Axis I Disorders, Research Version, Non-patient Edition. (SCID-I/NP) New York: Biometrics Research, New York State Psychiatric Institute, 2002.

42. Gorman LL, O'Hara MW, Figueiredo B, et al. Adaptation of the structured clinical interview for DSM-IV disorders for assessing depression in women during pregnancy and post-partum across countries and cultures. Br J Psychiatry Suppl 2004;46:s17-s23.

43. Cohen S, Kamarck T, Mermelstein R. A global measure of perceived stress. J Health Soc Behav 1983;24:385-96.

44. . Cohen S. http://www.psy.cmu.edu/ scohen/scales.html. 2012.

45. Dahlem NW, Zimet GD, Walker RR. The Multidimensional Scale of Perceived Social Support: a confirmation study. J Clin Psychol 1991;47:756-61.
46. Akhtar A, Rahman A, Husain M, et al. Multidimensional scale of perceived social support: psychometric properties in a South Asian population. J Obstet Gynaecol Res 2010;36:845-51.

47. Pascoe JM, lalongo NS, Horn WF, et al. The reliability and validity of the maternal social support index. Fam Med 1988;20:271-6.

48. Teti DM, Gelfand DM. Behavioral competence among mothers of infants in the first year: the mediational role of maternal self-efficacy. Child Dev 1991;62:918-29.

49. Hn L, Culture LSF. Context, and Maternal Self-Efficacy in Latina Mothers. Appl Dev Sci 2008;12:198-201.

50. Surkan PJ, Kawachi I, Ryan LM, et al. parenting self-efficacy, and child growth. Am J Public Health 2008;98:125-32.

51. Coleman PK, Karraker KH. Maternal self-efficacy beliefs, competence in parenting, and toddlers' behavior and developmental status. Infant Ment Health J 2003;24:126-48.

52. Ustün TB, Chatterji S, Kostanjsek N, et al. Developing the World Health Organization Disability Assessment Schedule 2.0. Bull World Health Organ 2010;88:815-23.

53. WHO. Multi-Country Study on Women's Health and Domestic Violence Study Protocol. Geneva: WHO, 2001.

54. Rahman A, lqbal Z, Harrington R. Life events, social support and depression in childbirth: perspectives from a rural community in the developing world. Psychol Med 2003;33:1161-7.

55. Beecham J, Knapp M. Costing Psychiatric Interventions, 2001.

56. Rahman A, Malik A, Sikander S, et al. Cognitive behaviour therapybased intervention by community health workers for mothers with depression and their infants in rural Pakistan: a cluster-randomised controlled trial. Lancet 2008;372:372:902-9.

57. Qadir F, Stewart R, Khan M, et al. The validity of the Parental Bonding Instrument as a measure of maternal bonding among young Pakistan women. Soc Psychiatry Psychiatr Epidemiol 2005;40:276-82.

58. Parker G. The Parental Bonding Instrument: psychometric properties reviewed. Psychiatr Dev 1989;7:317-35.

59. Centers for Disease Control and Prevention (CDC). Adverse childhood experiences reported by adults - five states, 2009. MMWR Morb Mortal Wkly Rep 2010;59:1609-13.

60. WHO. Adverse Childhood Experiences International Questionnaire (ACE-IQ). 2015 http://www.who.int/violence_injury_prevention/ violence/activities/adverse_childhood_experiences/en/.

61. WHO, UNICEF. Global Strategy for Infant and Young Child Feeding 2003.

62. WHO. Indicators for Assessing Infant and Young Child Feeding Practices: Part 1 Definitions. Geneva: World Health Organization, 2008.

63. Rasheed MA, Yousafzai AK. The development and reliability of an observational tool for assessing mother-child interactions in field studies- experience from Pakistan. Child Care Health Dev 2015;41:1161-71.

64. Caldwell B, Bradley R. Home observation for measurement of the environment: Administration manual. Tempe, AZ: Family \& Human Dynamics Research Institute, Arizone State University, 2003.

65. Yousafzai AK, Rasheed MA, Rizvi A, et al. and Emotional Availability: An RCT. Pediatrics 2015;135:e1247-e57.

66. Sarwat K A, Pervez A S. Adaptation of Home Inventory (Infant Version) For Pakistani Children. Pakistan Jouranl of Psychological Research 1991;6:103-15.

67. Nadeem S, Rafique G, Khowaja L, et al. Assessing Home Environment for Early Child Development in Pakistan. Child Care in Practice 2014;20:194-206.

68. Condon JT, Corkindale CJ. The assessment of parent-to-infant attachment: Development of a self-report questionnaire instrument. $J$ Reprod Infant Psychol 1998;16:57-76.

69. Goodman R. The Strengths and Difficulties Questionnaire: a research note. J Child Psychol Psychiatry 1997;38:581-6.

70. Goodman A, Lamping DL, Ploubidis GB. When to use broader internalising and externalising subscales instead of the hypothesised five subscales on the Strengths and Difficulties Questionnaire (SDQ): data from British parents, teachers and children. J Abnorm Child Psychol 2010;38:1179-91.

71. Woerner W, Fleitlich-Bilyk B, Martinussen R, et al. The Strengths and Difficulties Questionnaire overseas: evaluations and applications of the SDQ beyond Europe. Eur Child Adolesc Psychiatry 2004;13 Suppl 2:1147-54.

72. Syed EU, Hussein SA, Mahmud S. Screening for emotional and behavioural problems amongst 5-11-year-old school children in Karachi, Pakistan. Soc Psychiatry Psychiatr Epidemiol 2007;42:421-7

73. Samad L, Hollis C, Prince $M$, et al. Child and adolescent psychopathology in a developing country: testing the validity of the strengths and difficulties questionnaire (Urdu version). Int J Methods Psychiatr Res 2005;14:158-66. 
74. Squires J, Bricker D, Potter L. Revision of a parent-completed development screening tool: Ages and Stages Questionnaires. $J$ Pediatr Psychol 1997;22:313-28.

75. Singh A, Yeh CJ, Boone Blanchard S, Ages BBS. Ages and Stages Questionnaire: a global screening scale. Bol Med Hosp Infant Mex 2017;74:5-12.

76. Squires JK, Bricker DD, Twombly E. Ages and Stages Questionnaire: Social-Emotional (ASQ:SE): a parent-completed, child-monitoring system for social-emotional behaviors. Baltimore, MD: Paul H Brookes Publishing, 2002
77. Velikonja T, Edbrooke-Childs J, Calderon A, et al. The psychometric properties of the Ages \& Stages Questionnaires for ages 2-2.5: a systematic review. Child Care Health Dev 2017;43:1-17.

78. Bayley N, Reuner G. Bayley scales of infant and toddler development: Bayley-III.: Harcourt Assessment: Psych. Corporation, 2006.

79. NIPS. Pakistan Demographic and Health Survey. Islamabad, Pakistan: National Institute of Population Studies, 2012-13.

80. Ali TS, Asad N, Mogren I, et al. Intimate partner violence in urban Pakistan: prevalence, frequency, and risk factors. Int $\mathrm{J}$ Womens Health 2011;3:105-15. 